\title{
Is a Single Product Cost Function Appropriate for Institutions of Higher Education? Empirical Evidence From China's Research Universities*
}

\author{
Hou Longlong \\ Beijing Normal University, Beijing, China
}

\begin{abstract}
Many studies exist in the literature of scale and scope economies in institutions of higher education employing multi-product cost functions of quadratic, constant elasticity substitution (CES), or hybrid translog form. A single product cost function is normally considered inadequate and yield distorted results. Both quadratic and single product cost functions have been applied to university data from China's Ministry of Education (MOE). This study compares those two methods and their statistical results and finds that ray economies of scale from these two cost functions are quite similar though the single product cost function which can not be used to calculate product-specific economies of scale or economies of scope.

Keywords: single and multi-product cost function, economies of scale, economies of scope, China's research universities
\end{abstract}

\section{Introduction and Literature Review}

Since the seminal work of Baumol, Panzar, and Willig (1982), researchers have performed many economic analyses on multi-product organizations. In higher education, different forms of multi-product cost function have been employed to calculate economies of scale and economies of scope. Firstly, a quadratic cost function has been used by Cohn, Rhine, and Santos (1989); Lloyd, Morgan, and Williams (1993); Dundar and Lewis (1995); Lewis and Dundar (1995); Johnes (1996; 1998); Hashimoto and Cohn (1997); R. K. Koshal and M. Koshal (1999; 2000; 2001); Laband and Lentz (2003); Hou, Li, and Min (2009); Duch, Parellada, and Polo (2010); Worthington and Higgs (2011); and Khan (2012). Alternatively, a constant elasticity substitution (CES) cost function was used by Johnes (1997a; 1997b) and Izadi, Johnes, Oskrochi, and Crouchley (2002). Finally, a hybrid translog cost function has also been employed by Glass, McKillop, and Hyndman (1995). The single product cost function has been discarded by researchers. Cohn et al. (1989) not only conducted the first study to examine multiple outputs in institutions of higher education, but compared the results for single-equation and multi-product models. They concluded that the single-output model might provide misleading results.

\footnotetext{
* Project supported: This paper is granted by Beijing Social Science Fund research base project "The Efficiency Study on Capital University Running Quality" (Project No. 14JDJYB007).

Hou Longlong, Ph.D., associate professor at Faculty of Education, Beijing Normal University, Beijing, China.

Correspondence concerning this article should be addressed to Hou Longlong, Haidian District, Xinjiekouwai Street, No. 19, Faculty of Education, Beijing Normal University, Beijing 100875, China.
} 
The purpose of this paper is to estimate both quadratic and single product cost functions. Using new evidence from China's higher education, this paper reexamines analysis of Cohn et al. (1989) dealing with the single-equation model. This study should be useful in three respects. First, with new evidence, this paper can examine whether a single product cost function is applicable to estimation of institutions of higher education. Second, this study can facilitate a comparison of higher education costs across countries. Third, it will be helpful to evaluate internal efficiency for higher education decision-makers as there are no previous similar studies of China's higher education.

The plan of this paper is as follows: The next section describes the methodology used in this study; next it explains the data employed; then, the results from single and multi-product cost functions are discussed and compared; and the final section summarizes the conclusions and gives suggestions for future work.

\section{Methodology}

\section{Multi-product Cost Function}

This study uses both single and multi-product cost functions. For the multi-product cost function, it followed Baumol et al. (1982); Cohn et al. (1989); R. K. Koshal and M. Koshal (1999; 2000; 2001), and Laband and Lentz (2003), by employing a flexible fixed cost quadratic (FFCQ) function. ${ }^{1}$ This study believes that the standard translog cost function is not suitable for this study, because it does not permit any zero output. So it can not compute the average incremental cost and economies of scope defined below. Thus, the function is of the following form:

$$
T C=a_{0}+\sum_{i=1}^{k} a_{i} Q_{i}+\frac{1}{2} \sum_{i=1}^{k} \sum_{j=1}^{k} b_{i j} Q_{i j}+c_{1} F S+c_{2} \sum_{i=1}^{k} Q_{i} F S+c_{3} F S^{2}+d C S I Z E+V
$$

where $T C$ is the total cost of producing $k$ products; $a_{0}$ is a constant; $a_{i}$ and $b_{i j}$ are coefficients associated with various output variables; $Q_{i}$ is the output of the $i$-th product; $c_{1}, c_{2}$, and $c_{3}$ are the coefficients of input factor average faculty salary $F S$, the interaction between faculty salary and $Q_{i}$ and the square of average faculty salary; the coefficient of CSIZE is $d$, where CSIZE is the ratio of numbers of students and teachers; and $V$ is a random error term. ${ }^{2}$

\section{Economies of Scale and Scope for Multiple Outputs}

Generally, like U.S., Great Britain, Australia, Japan, Turkey, etc., China's higher education also can be seen as multi-product organization. This study uses three products to characterize China's institutions of higher education: $Q_{U}$-undergraduate students, $Q_{G}$-graduate students, and $Q_{R}$-research activities.

Definitions of economies of scale and economies of scope were provided by Baumol et al. (1982). Following Baumol et al. (1982); Cohn et al. (1989); De Groot, McMahon, and Volkwein (1991); Nelson and Heverth (1992); Dundar and Lewis (1995); R. K. Koshal and M. Koshal (1999; 2000; 2001); and Laband and Lentz (2003), this paper first defines the average incremental cost (AIC) for undergraduate output as:

\footnotetext{
${ }^{1}$ Baumol et al. (1982, pp. 448-463) have discussed the desiderata for multi-product cost function and given three popular specific cost forms as the quadratic, CES, and hybrid translog functions. Studies which have employed these three forms have been identified in the "introduction" section of our paper.

2 Although the author employs the FFCQ function, there are no dummy variables according to different outputs in its specification. Because each output across the universities in the sample is all positive. In section 3, this paper will describe the homogeneity of the sample data.
} 


$$
A I C_{U}=\frac{T C\left\{Q_{U}, Q_{G}, Q_{R}\right\}-T C\left\{0, Q_{G}, Q_{R}\right\}}{Q_{U}}
$$

where $T C\left\{Q_{U}, Q_{G}, Q_{R}\right\}$ is the total cost of producing $Q_{U}$ units of undergraduate students, $Q_{G}$ units of graduate students, and $Q_{R}$ units of research; $T C\left\{0, Q_{U}, Q_{G}\right\}$ is the total cost when output for product $U$ is zero. Similarly, average incremental costs for products $G\left(A I C_{G}\right)$ and $R\left(A I C_{R}\right)$ are defined. As in the case of a single product, economies of scale are measured by the ratio of average to marginal costs. Economies of scale are said to exist when this ratio is greater than one. Baumol et al. (1982) made a distinction between two different types of economies of scale: ray-economies and product-specific economies of scale. The product-specific economies of scale for product $U$ are defined as

$$
E_{U}=\frac{A I C_{U}}{M C_{U}}
$$

where $M C_{U}=\partial T C / \partial Q_{U}$ is the marginal cost of producing product $U$. If $E_{U}$ is greater (smaller) than one, economies (diseconomies) of scale are said to exist for the product $U$. Ray (overall ) economies of scale (RE) may exist when the quantities of all products are increased proportionally. Ray economies of scale are defined as follows:

$$
R E=\frac{T C\left\{Q_{U}, Q_{G}, Q_{R}\right\}}{Q_{U} M C_{U}+Q_{G} M C_{G}+Q_{R} M C_{R}}
$$

Ray economies (diseconomies) of scale are said to exist, when $R E$ is greater (less) than one.

In any production process, economies of scope are present when there are cost efficiencies to be gained by joint production for multiple products, rather than by being produced separately (Panzar \& Willig, 1981). Following Dundar and Lewis (1995); Hashimoto and Cohn (1997); R. K. Koshal and M. Koshal (1999; 2000; 2001), economies of scope are divided into global and product-specific economies of scope. The degree of global economies of scope $(G E)$ in the production of all products is defined as

$$
G E=\frac{T C\left\{Q_{U}, 0,0\right\}+T C\left\{0, Q_{G}, 0\right\}+T C\left\{0,0, Q_{R}\right\}-T C\left\{Q_{U}, Q_{G}, Q_{R}\right\}}{T C\left\{Q_{U}, Q_{G}, Q_{R}\right\}}
$$

Global economies (diseconomies) of scope are said to exist, if $G E$ is greater (less) than zero. Cost advantages due to production of each product jointly with the other outputs are called product-specific economies of scope (PSE), for example, for product $U$, this is given by

$$
P S E_{U}=\frac{T C\left\{Q_{U}, 0,0\right\}+T C\left\{0, Q_{G}, Q_{R}\right\}-T C\left\{Q_{U}, Q_{G}, Q_{R}\right\}}{T C\left\{Q_{U}, Q_{G}, Q_{R}\right\}}
$$

Product-specific economies (diseconomies) of scope associated with product $U$ are said to exist, if $P S E_{U}$ is greater (smaller) than zero.

\section{Single Product Cost Function}

Following Cohn et al. (1989), a single product model can be written in a form similar to that of a quadratic cost function: 


$$
C=a_{0}+b_{1} Y+b_{2} W+c_{11} Y^{2}+c_{22} W^{2}+c_{12} Y W+U
$$

where the scalar 0.5 has been omitted for simplicity; $C$ is the total cost of producing $Y$ outputs of product; $a_{0}$ is a constant; $b_{1}$ and $b_{2}$ are coefficients associated with output $Y$ and input factor $W$ variables. Unlike Cohn et al. (1989), this study calculates $Y$ through weighted values of undergraduate and graduate students: The procedure is discussed below. $W$ is set equal to average faculty salary $(F S)$. The coefficients of $Y$ squared and $W$ squared are $c_{11}$ and $c_{22} ; c_{12}$ is the coefficient of interaction between $Y$ and $W$. $U$ is a random error term.

For the single product model, Cohn et al. (1989) used $\left(Q_{U}+Q_{G}\right)$ as the proxy for $Y$, where the number of graduate students is added directly to that of undergraduate students. This study thinks that this treatment is inappropriate because graduate and undergraduate students are not homogenous and represent different costs and outputs; otherwise, this paper does not need to distinguish them in the multiple outputs case. According to Baumol et al. (1982), earlier approaches for single-product techniques involved aggregation of the different outputs of the firms into a single measure, the "scalar output", using value weights, value-added weights, or weights related to some physical characteristic of the various outputs, such as size. So unlike Cohn et al. (1989), this study gives weights to every graduate student. Specifically, this study lets one graduate student equal 7.22 undergraduate students. ${ }^{3}$

\section{Economies of Scale and Scope for Single Output}

According to the definition of economies of scale for a single output, economies (diseconomies) of scale occur in the region, when the average cost is decreasing (increasing). The average cost is $C / Y$ :

$$
\frac{C}{Y}=\frac{a_{0}}{Y}+b_{1}+b_{2} \frac{W}{Y}+c_{11} Y+c_{22} \frac{W^{2}}{Y}+c_{12} \frac{W^{2}}{Y}
$$

while the condition for the decreasing (increasing) $C / Y$ is that the first partial derivative $\frac{\partial(C / Y)}{\partial Y}$ is less (greater) than zero. The first partial derivative is as follows:

$$
\frac{\partial(C / Y)}{\partial Y}=-\frac{a_{0}}{Y^{2}}-b_{2} \frac{W}{Y^{2}}+c_{11}-c_{22} \frac{W^{2}}{Y^{2}}
$$

so economies (diseconomies) of scale are said to exist when (3') is less (greater) than zero. When (3') is equal to zero, economies (diseconomies) of scale are exhausted.

Additionally, economies of scale $(R E)$ may exist, when the quantities of the product are increased proportionally. Following Baumol et al. (1982), economies of scale are defined as follows:

$$
S=\frac{C(Y)}{Y[d C(Y) / d Y]}=\frac{C\left(\sum a_{i} y_{i}\right)}{Y\left[d C\left(\sum a_{i} y_{i}\right) / d Y\right]} \text { and } Y=\sum a_{i} y_{i}
$$

Ray economies (diseconomies) of scale are said to exist when $S$ is greater (less) than one. The strength of this formula is that this study can compute the degree of economies of scale.

\footnotetext{
${ }^{3}$ How much value should each output be weighted? The author based the weighting scheme on some statistical basis. In section 4 , it estimates the three-output model first and gets the average incremental cost of graduate and undergraduate. The ratio of average cost for one graduate student on one undergraduate student is about 7. It employs the weighted average number (which is 7.22) of the ratios across different mean output levels here (see the multi-product model in section 4).
} 
Because there is only one single output here, there is no distinction between ray- and product-specific economies of scale. Similarly, economies of scope including global and product-specific economies of scope cannot be calculated. ${ }^{4}$

\section{Data}

As of 2000, there were 1,041 regular institutions of higher education in China, enrolling 5,560,900 students. Among these institutions of higher education, there were 116 universities under central ministries and agencies and 925 institutions under local authorities. In the 116 universities, there are 72 institutions under Ministry of Education (MOE, 2004), enrolling 868,009 students (Development Department of the Ministry of Education, 2000). Unfortunately, data availability for this study is quite limited. The data used here came from the cross-sectional gathering of data of universities under MOE. This paper argues that the universities in this sample are all research oriented. According to the evaluation of Chinese universities for 2000 and the "211 project" plan, the research performance of universities in the sample is at the top of $7 \%$ of Chinese universities (Wu, Lu, \& Guo, 2001; China Education and Research Network, 2004) ${ }^{5}$. The data included information on appropriate funds from MOE, expenditure for teaching and research, expenditure for personnel, the numbers of all kinds of students, the administrative and financial conditions of universities, etc. The consistent and usable sample size is 74 universities. $^{6}$ As to the homogeneity of outputs, this paper suggests that all the sample universities have similar goals in teaching and research. As R. K. Koshal and M. Koshal's study (1995) showed, the output quality is important variable in explaining the average total cost and output relation. This study has not controlled the quality differences because of data limitation. While future work should probe this matter further, the present study will focus exclusively on obtained for the pooled sample universities.

In higher education, as pointed out by Cohn et al. (1989), there is no consensus on appropriate measures of output. For the purpose of our analysis, this study assumes three outputs in higher education: (1) first degree graduates represented by the number of full-time equivalent undergraduate students $\left(Q_{U}\right)$; (2) advanced degree graduates represented by the number of full-time equivalent graduate students $\left(Q_{G}\right)$; and (3) the level of research output indicated by research expenditure measured in Yuan (Ren Min Bi, $Q_{R}$ ). $Q_{U}$ includes all undergraduate students enrolled as freshmen, sophomores, juniors, and seniors. $Q_{G}$ includes all master's and doctoral students. The measurement of research output is controversial. Although no direct measure exists, the use of an input (research expenditure) as an indicator of research output (such as publications, research reports, patents, public lectures, and other results of one's research work) is contentious. In its defence, one would note that research grants are in general awarded to meritorious groups of researchers on the basis of the quality and quantity of their previous work. Although in some instances, research funds are expended for other than research (e.g., training), and, further, while research can proceed without outside grants, etc., there should be a high correlation between research output and research expenditure. In the absence of a better alternative, the

\footnotetext{
${ }^{4}$ Or it can be said that the calculations of economies of scope (both global and product-specific) are the same as multi-product model. What people need to do is just to divide output $Y$ into original undergraduate and graduate student numbers. That means that it transforms from single output model to multi-product model.

5 The research performance is measured by scores of natural sciences and social sciences based on all kinds of research activities (like publications, patents and research income, etc.). Although the sample size is not large, the universities under MOE are quite different from others. So the author felt that the information from this sample is quite important despite its shortcomings.

${ }^{6}$ There are 72 universities under MOE in 2000 and three of them have two school districts located in different places. The data are reported separately and independently for those different districts. Besides, there is one university's data missing. So the usable sample size is 74 observations.
} 
best available measure for this study is the amount of research funds that the faculties expend. The total cost variable used here (TC) is measured by each university's current expenditure for teaching and research. Definitions of variables and some basic descriptive statistics for multi- and single-output cases in this study are presented in Table 1 and Table 2.

This paper does not use the dummy variables for undergraduate teaching, graduate teaching, or research activities, because all of the sample universities are engaged in all these activities.

Table 1

Description of Variables and Summary of Statistics for Multi-product Case

\begin{tabular}{llrr}
\hline Variables & Description & \multicolumn{1}{c}{ Mean } & Standard deviation \\
\hline$T C$ & Total cost in millions of Yuan (RMB) & 319.0024 & 288.0358 \\
$Q_{R}$ & Research expenditure in millions of Yuan & 58.4539 & 75.4902 \\
$Q_{R}{ }^{2}$ & Research expenditure squared & $9,038.6177$ & $30,212.0738$ \\
$Q_{U}$ & Undergraduate FTE in thousands & 10.7896 & 7.4764 \\
$Q_{U}{ }^{2}$ & Undergraduate FTE squared & 171.5584 & 245.1111 \\
$C S I Z E$ & Students per teacher & 12.2351 & 3.2641 \\
$Q_{G}$ & Graduate FTE in thousands & 2.1192 & 2.0215 \\
$Q_{G}{ }^{2}$ & Graduate FTE squared & 8.5222 & 15.7497 \\
$F S$ & Average faculty salary in hundreds of Yuan & 24.9449 & 8.3750 \\
$F S^{2}$ & Average faculty salary squared & 691.4408 & 524.4500 \\
$Q_{U} \times Q_{G}$ & Undergraduate FTE $\times$ Graduate FTE & 32.9333 & 49.9083 \\
$Q_{U} \times F S$ & Undergraduate FTE $\times$ Average faculty salary & 271.2469 & 208.5725 \\
$Q_{U} \times Q_{R}$ & Undergraduate FTE $\times$ Research expenditure & 869.8137 & $1,356.3275$ \\
$Q_{G} \times F S$ & Graduate FTE $\times$ Average faculty salary & 60.0807 & 76.3583 \\
$Q_{G} \times Q_{R}$ & Graduate FTE $\times$ Research expenditure & 250.0088 & 601.3719 \\
$Q_{R} \times F S$ & Research expenditure $\times$ Average faculty salary & $1,748.6398$ & $3,322.7744$ \\
\hline
\end{tabular}

Note. ${ }^{\mathrm{a}}$ in the sample universities data, the teacher number used here includes both teaching and research faculties.

Table 2

Description of Variables and Summary of Statistics for Single Product Case

\begin{tabular}{lccrc}
\hline & Minimum value & Maximum value & Mean & Standard deviation \\
\hline Total cost in millions of Yuan $(\mathrm{RMB})$ & 23.7900 & $1,592.4300$ & 319.0024 & 288.0358 \\
Output $Y$ in thousands of students & 0.7292 & 84.5618 & 26.0903 & 20.4031 \\
Average faculty salary in hundreds of Yuan & 14.22 & 58.62 & 24.9449 & 8.3750 \\
Output $Y$ squared $\left(Y^{2}\right)$ & 0.5318 & $7,150.7048$ & $1,091.3658$ & $1,665.3834$ \\
Average faculty salary squared $\left(W^{2}\right)$ & 202.1231 & $3,435.8355$ & 691.4408 & 524.45 \\
Output $Y \times$ Average faculty salary $(Y \times W)$ & 10.6977 & $3,567.2308$ & 705.0294 & 719.8499 \\
\hline
\end{tabular}

\section{Statistical Results}

\section{Multi-product Model}

Using the above data and applying multiple regression techniques, this study first estimates the quadratic multi-product cost function like equation (1). The results from estimating the three-output FFCQ functions are given in Table 3. Equations (7), (8), and (9) in Table 3 are different forms of three-output FFCQ functions like equation (1). The values on the right of the coefficients are $t$-values and its significance. Adj- $R^{2}$ is the coefficient of determination adjusted for the degree of freedom. The $F$-ratio tests the overall fit of the equation. 
Equations (7), (8), and (9) are as follows:

$$
\begin{aligned}
& T C=a_{0}+a_{1} Q_{R}+a_{2} Q_{U}+a_{3} Q_{G}+b_{1} Q_{R}^{2}+b_{2} Q_{U}^{2}+b_{3} Q_{G}^{2}+b_{4} Q_{R} Q_{U}+b_{5} Q_{U} Q_{G}+b_{6} Q_{R} Q_{G} \\
& T C=a_{0}+a_{1} Q_{R}+a_{2} Q_{U}+a_{3} Q_{G}+b_{1} Q_{R}^{2}+b_{2} Q_{U}^{2}+b_{3} Q_{G}^{2}+b_{4} Q_{R} Q_{U}+b_{5} Q_{U} Q_{G}+b_{6} Q_{R} Q_{G} \\
& +c_{1} F S+c_{2} F S^{2}+c_{3} Q_{U} F S+c_{4} Q_{G} F S+c_{5} Q_{R} F S \\
& T C=a_{0}+a_{1} Q_{R}+a_{2} Q_{U}+a_{3} Q_{G}+b_{1} Q_{R}^{2}+b_{2} Q_{U}^{2}+b_{3} Q_{G}^{2}+b_{4} Q_{R} Q_{U}+b_{5} Q_{U} Q_{G}+b_{6} Q_{R} Q_{G} \\
& +c_{1} F S+c_{2} F S^{2}+c_{3} Q_{U} F S+c_{4} Q_{G} F S+c_{5} Q_{R} F S+d C S I Z E
\end{aligned}
$$

\begin{tabular}{|c|c|c|c|c|c|c|}
\hline \multirow[b]{2}{*}{ Intercept } & \multicolumn{2}{|c|}{$\begin{array}{l}\text { Equation (7) coefficients, } \\
t \text {-values and significance }\end{array}$} & \multicolumn{2}{|c|}{$\begin{array}{l}\text { Equation (8) coefficients, } \\
t \text {-values and significance }\end{array}$} & \multicolumn{2}{|c|}{$\begin{array}{l}\text { Equation (9) coefficients, } \\
t \text {-values and significance }\end{array}$} \\
\hline & 39.912 & $2.302^{* *}$ & -33.856 & -0.713 & -44.625 & -0.965 \\
\hline$Q_{R}$ & 1.181 & $2.58^{* *}$ & 1.161 & 1.325 & 1.46 & $1.7^{*}$ \\
\hline$Q_{R}{ }^{2}$ & $-1.33 \mathrm{E}-03$ & -0.557 & $-3.91 \mathrm{E}-03$ & $-1.892^{*}$ & $-3.18 \mathrm{E}-03$ & -1.565 \\
\hline$Q_{U}$ & 2.168 & 0.546 & 11.134 & $2.17^{* *}$ & 14.21 & $2.758^{* * *}$ \\
\hline$Q_{U}^{2}$ & 0.472 & $2.487^{* *}$ & 0.473 & $3.472^{* * *}$ & 0.371 & $2.661^{* * *}$ \\
\hline$Q_{G}$ & 70.75 & $3.519^{* * *}$ & -7.745 & -0.219 & -27.678 & -0.782 \\
\hline$Q_{G}^{2}$ & 2.776 & 0.445 & 1.752 & 0.299 & 0.375 & 0.066 \\
\hline$Q_{U} \times Q_{G}$ & -3.077 & $-2.207^{* *}$ & -2.251 & -1.577 & -1.4 & -0.977 \\
\hline$Q_{U} \times Q_{R}$ & $8.02 \mathrm{E}-04$ & 0.025 & $-3.02 \mathrm{E}-03$ & -0.099 & $-1.92 \mathrm{E}-02$ & -0.63 \\
\hline$Q_{G} \times Q_{R}$ & 0.179 & 0.729 & 0.212 & 1.121 & 0.238 & 1.298 \\
\hline$F S$ & & & 4.012 & 1.117 & 7.303 & $1.934^{*}$ \\
\hline$F S^{2}$ & & & $-1.82 \mathrm{E}-02$ & -0.28 & $-6.11 \mathrm{E}-02$ & -0.93 \\
\hline$Q_{U} \times F S$ & & & -0.329 & $-1.688^{* *}$ & -0.36 & $-1.906^{*}$ \\
\hline$Q_{G} \times F S$ & & & 2.048 & 1.506 & 2.605 & $1.945^{*}$ \\
\hline$Q_{R} \times F S$ & & & $1.31 \mathrm{E}-02$ & 0.371 & $-3.36 \mathrm{E}-03$ & -0.096 \\
\hline CSIZE & & & & & -3.609 & $-2.232^{* *}$ \\
\hline$R^{2}$ & 0.971 & & 0.989 & & 0.990 & \\
\hline $\operatorname{Adj}-R^{2}$ & 0.967 & & 0.987 & & 0.988 & \\
\hline ( $F$-ratio) & $241.716^{* * *}$ & & $386.983^{* * *}$ & & $385.899^{* * *}$ & \\
\hline$n$ & 74 & & 74 & & 74 & \\
\hline
\end{tabular}

Table 3

Three-Output Quadratic Cost Function

Notes. ${ }^{*}$ denotes $10 \%$ level of significance; ${ }^{* *}$ denotes $5 \%$ level of significance; and ${ }^{* * *}$ denotes $1 \%$ level of significance.

Statistically, the results of equation (7) in Table 3 are significant with the exception of the relevant coefficient on $Q_{U}, Q_{G}^{2}, Q_{R}^{2}, Q_{U} \times Q_{R}$ and $Q_{G} \times Q_{R}$. After adding average faculty salary (FS) in equations (8) and (9), the coefficients of $Q_{G}$ and $Q^{2}{ }_{G}$ become insignificant. This study suggests that this should be caused by too many variables estimated in a function with a relative small sample size. But this has not told the entire story about the relationship between the cost and output. Equation (8) includes average faculty salary as proxy for input factor price. Because faculty salaries constitute a high proportion of the total cost of higher education, they are the dominant factor cost. Equation (9) includes both average faculty salary (FS) and students per teacher (CSIZE). 
Following R. K. Koshal and M. Koshal (1999; 2000; 2001), the residuals of each equation were tested for heteroscedacity. The Breusch-Pagan-Godfrey test (Gujarati, 1995) was applied to the residuals of equations (7)-(9). Equation (7) excludes average faculty salary (FS) and students per teacher (CSIZE). Although its results are statistically significant and the coefficients have the expected sign, this test shows the presence of heteroscedacity.

The Breusch-Pagan-Godfrey test indicates that the residuals of equation (8) as well as those of equation (9) are homoscedastic. Consequently, the coefficients of these equations can be regarded as unbiased and efficient. By virtue of the higher Adj- $R^{2}$ and full variables employing for equation (9) than for equation (8), this paper has focused the discussion that follows on the results from equation (9) and used it as a basis for the various calculations of economies of scale and scope.

A main problem for the multi-product case is that there is no direct analogy to the "average cost" concept in the single product case (Cohn et al., 1989; Hashimoto \& Cohn, 1997; R. K. Koshal \& M. Koshal, 1999; 2000; 2001). However, as discussed earlier, the nearest analogy is provided by the average incremental cost (AIC). The AIC computation is based on the formulas specified in equation (2). ${ }^{7}$

The estimates for the values of ray and product-specific economies of scale are obtained from the formulas specified in equations (3) and (4). The results are summarized in Table 4.

Table 4

Ray and Product-Specific Economies of Scale

\begin{tabular}{lllll}
\hline$\%$ of mean output & $E_{R A Y}$ & $E_{U}$ & $E_{G}$ & $E_{R}$ \\
\hline 10 & 3.5269 & 0.9288 & 0.9979 & 1.0135 \\
50 & 1.4325 & 0.7216 & 0.9894 & 1.0692 \\
100 & 1.1426 & 0.5624 & 0.9789 & 1.1422 \\
150 & 1.0294 & 0.4593 & 0.9685 & 1.2195 \\
160 & 1.0136 & 0.4429 & 0.9665 & 1.2355 \\
170 & 0.9993 & 0.4276 & 0.9644 & 1.2517 \\
200 & 0.9627 & 0.3871 & 0.9583 & 1.3014 \\
250 & 0.9162 & 0.3338 & 0.9481 & 1.3884 \\
300 & 0.8807 & 0.2928 & 0.9381 & 1.4809 \\
500 & 0.7905 & 0.1934 & 0.8989 & 1.9180 \\
\hline
\end{tabular}

Notes. $E_{R A Y}$ is ray economies of scale; $E_{U}$ is undergraduate economies of scale; $E_{G}$ is graduate economies of scale; $E_{R}$ is research activity economies of scale; and average faculty salary $(F S)$ is set to the mean value in all the calculations.

From equations (3) and (4), ray and product-specific economies of scale occur, when the scale coefficient is greater than one. The above results suggest that there exist diseconomies of scale for undergraduates and graduates at all levels of outputs. Research activities exhibit economies of scale at all levels of output. For ray economies of scale, there exists a critical (threshold) level for the output. Ray economies of scale appear only apply, when the output level is equal to or smaller than $160 \%$ of the mean output value; and ray diseconomies of scale are shown when the output level is greater than $160 \%$ of mean output value.

Estimates for the values of global and product-specific economies of scope are obtained from the formulas given in equations (5) and (6). The results are summarized in Table 5.

\footnotetext{
7 This paper does not list the tables for marginal cost and average incremental cost here because of article's length limitation. If any reader is interested in the results, one could contact with the first author through email.
} 
Table 5

Global and Product-Specific Economies of Scope

\begin{tabular}{lllll}
\hline \% of mean output & $E S G$ & $E S_{U}$ & $E S_{G}$ & $E S_{R}$ \\
\hline 10 & 1.4398 & 0.7247 & 0.7193 & 0.7167 \\
50 & 0.6831 & 0.3961 & 0.3344 & 0.3049 \\
100 & 0.4333 & 0.3431 & 0.2002 & 0.1318 \\
125 & 0.3774 & 0.3502 & 0.1677 & 0.0803 \\
150 & 0.3412 & 0.3662 & 0.1451 & 0.0393 \\
180 & 0.3132 & 0.3917 & 0.1260 & -0.0011 \\
200 & 0.3008 & 0.4109 & 0.1165 & -0.0243 \\
250 & 0.2831 & 0.4624 & 0.0998 & -0.0737 \\
300 & 0.2770 & 0.5157 & 0.0894 & -0.1146 \\
350 & 0.2772 & 0.5683 & 0.0827 & -0.1497 \\
500 & 0.2946 & 0.7151 & 0.0734 & -0.2336 \\
600 & 0.3115 & 0.8021 & 0.0716 & -0.2779
\end{tabular}

Notes. $E S G$ is global economies of scope; $E S_{U}$ is undergraduate economies of scope; $E S_{G}$ is graduate economies of scope; $E S_{R}$ is economies of scope for research activities; and average faculty salary $(F S)$ was set to the mean value in all the calculations.

According to equations (5) and (6), global and product-specific economies of scope arise when the coefficients of economies of scope are greater than zero. The above results suggest that there exist global economies of scope and economies of scope for undergraduate and graduate students at all levels of outputs. For research activities, there exists a critical level of output for economies of scope: Economies appear only when the level of output is less than $180 \%$ of the mean output value; diseconomies arise when the output level becomes equal to or greater than $180 \%$.

\section{Single Product Model}

For the single product model, using data with only one output, this paper estimated the results for model (1') as follows (standard error in parentheses):

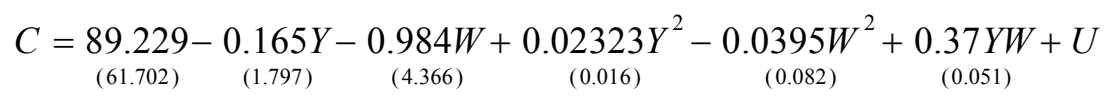

where $R^{2}=0.948, \operatorname{Adj}-R^{2}=0.944, F$-ratio $=247.207$, and $N=74$.

According to the formula specified in equation ( $\left.3^{\prime}\right)$, the first partial derivative $\frac{\partial(C / Y)}{\partial Y}$ is as follows:

$$
\frac{\partial(C / Y)}{\partial Y}=\frac{-89.229}{Y^{2}}+\frac{0.984 W}{Y^{2}}+0.02323+\frac{0.0395 W^{2}}{Y^{2}}
$$

The results for different levels of mean outputs are summarized in Table 6 .

An alternative measure of economies of scale for a single output is suggested by Baumol et al. (1982). For this, estimates for the values of economies of scale are computed based on the formula shown in equation (4'). The results are also summarized in Table 6 .

As stated earlier, economies (diseconomies) of scale are said to exist when (3') is less (greater) than zero. When (3') is equal to zero, economies (diseconomies) of scale are exhausted. The above results suggest that 
there exist economies of scale at the mean value of output. For the value of $\frac{\partial(C / Y)}{\partial Y}$ equal to zero, the single output $Y$ has the value 40.136 (i.e., 40,136 students $^{8}$ ). So when the single output $Y$ equals to 40.136 , which is at about the $160 \%$ level of mean output, economies of scale are exhausted. Ray economies of scale are present below this level and diseconomies of scale above it.

Table 6

Rate of Change of Average Cost of Single Output With Scale and Indicators for Economies of Scale, Degrees of Economies of Scale, Marginal Costs and Average Costs for Single Output Model

\begin{tabular}{|c|c|c|c|c|c|}
\hline$\%$ of mean output & $\frac{\partial(C / Y)}{\partial Y}$ & $E_{R A Y}(E / D)$ & $E_{R A Y}$ & $M C$ (Yuan) & $A C$ (Yuan) \\
\hline 10 & -5.8684 & $E$ & 2.6668 & 9,186 & 24,497 \\
\hline 50 & -0.2124 & $E$ & 1.2866 & 9,671 & 12,442 \\
\hline 100 & -0.0357 & $E$ & 1.0906 & 10,277 & 11,208 \\
\hline 150 & -0.0030 & $E$ & 1.0106 & 10,883 & 10,998 \\
\hline 160 & 0.0002 & $D$ & 0.9992 & 11,004 & 10,995 \\
\hline 170 & 0.0028 & $D$ & 0.9887 & 11,125 & 10,999 \\
\hline 200 & 0.0085 & $D$ & 0.9614 & 11,489 & 11,045 \\
\hline 250 & 0.0138 & $D$ & 0.9256 & 12,095 & 11,195 \\
\hline 300 & 0.0167 & $D$ & 0.8972 & 12,701 & 11,395 \\
\hline 500 & 0.0209 & $D$ & 0.8200 & 15,125 & 12,402 \\
\hline
\end{tabular}

Notes. $E_{R A Y}$ is ray economies of scale; $E$ represents existence of ray economies of scale; $D$ represents existence of ray diseconomies of scale; $M C$ is marginal cost of single output $Y$; $A C$ is average cost of single output $Y$; and average faculty salary $(W)$ was set to the mean value in all the calculations.

According to equation (4'), ray economies (diseconomies) of scale occur, when the scale coefficient is greater than one. The above results indicate that there exists a critical (threshold) level for the single output $Y$. Economies of scale only apply when the output level is smaller than $160 \%$ of mean output value and diseconomies of scale are present when the output level is equal to or greater than $160 \%$ of mean output value. This finding is also consistent with the results from equation (3'). The marginal cost for the single output $Y$ varies between 9,186 Yuan (RMB) and 15,125 Yuan (RMB). The average cost varies between 10,995 Yuan (RMB) and 24,497 Yuan (RMB).

\section{Comparison of Single and Multi-product Models}

According to Table 4, ray economies of scale for the three-output model apply only when the output level is equal to or smaller than $160 \%$ of the mean output value; and ray diseconomies of scale are present when the output level is greater than $160 \%$ of the mean output value. At the critical level of $160 \%$ of mean output value, there are 17,263 undergraduate students $\left(Q_{U}=17.263\right.$ thousand) and 3,390 postgraduate students $\left(Q_{G}=3.39\right.$ thousand). These numbers correspond to the weighted value for $Y$ in the single product case of:

$$
Y=17,263+7.22 \times 3,390=41,739
$$

According to Table 6, ray economies of scale for the single output model apply only when the output level is smaller than $160 \%$ of the mean output value and diseconomies of scale are present when the output level is

${ }^{8}$ This includes undergraduate students and weighted postgraduate students. 
equal to or greater than $160 \%$ of the mean output value. At the critical level of $160 \%$ of mean output value, there are about 40,136 students, which is quite close to the results for the three-output model, within $4 \%$ of the number derived from the three output model. ${ }^{9}$

From this comparison, it appears that there is no significant difference between multi- and single product models results for ray economies of scale. The only shortcoming for the single product model is that economies of scope including global and product-specific economies of scope cannot be calculated. If results of economies of scope are wondered, the author has to change from the single output into two or multi-product model. ${ }^{10}$ Of course, there is no distinction between ray- and product-specific economies of scale for the single output.

\section{Conclusions}

The primary concern in this study was to examine whether economies of scale and scope existed in China's research universities which are under MOE; and if they did exist, to what extent and what effect. This study employed both multi-product quadratic and single product cost functions and compared the results from these estimates. The main findings show that there exist ray economies of scale below $160 \%$ of mean output levels and ray diseconomies of scale only above $160 \%$ of mean output levels. This is confirmed by both the three-output and single output model. That suggests that there is still space to save cost through increasing the average size of the universities under MOE. For the larger universities in which total weighted student number is over about 40,136-41,739, cost inefficiencies may appear. These results are comparable with previous studies of Dundar and Lewis (1995); Cohn et al. (1989); Hashimoto and Cohn (1997); R. K. Koshal and M. Koshal (1999; 2000; 2001); Laband and Lentz (2003); Hou et al. (2009); Duch et al. (2010); Worthington and Higgs (2011); and Khan (2012).

The presence of product-specific economies of scale for research activities but not for undergraduate and graduate students implies that research activities should be more highly concentrated in a small number of institutions, while the teaching activities should be more decentralized in a large number of universities. In summary, given the level of total input resources, greater economies could be realized by reallocating outputs across universities.

The findings on presence of global economies of scope and product-specific economies of scope for undergraduate and postgraduate students at all levels of outputs show that the synergies of teaching and research activities could save cost. This provides evidence to support for the commonly belief of the multi-dimensional nature of higher education system. Besides, the results imply that for research, product-specific economies and diseconomies of scope exist depending on the output level. They vary at a value of $180 \%$ of the mean output which means that the joint production of teaching and research may cause inefficiencies after certain level of outputs.

\footnotetext{
${ }^{9}$ In some cases (e.g., data limitation), it is inconvenient to use multi-product model, so the author does not know exactly how much the weighting scheme should be, when he employs a single output model. Under this condition, some experimental numbers will be very useful, the ratio used in government is such a kind of number. The author chooses to use values of 1 to every undergraduate student, 1.5 to each master's student, and 2 per doctoral student based on a document by MOE in 2004 (MOE, 2004). He re-estimates and calculates the ray economies of scale for single product case. The results still support the finding that both single and multiple output models do not differ significantly though the critical weighted student number changes from about 41,000 to 24,000 .

${ }^{10}$ For the two output model, the computation of scale and scope economies can be seen in R. K. Koshal and M. Koshal's study (2001).
} 
Overall, the study indicates that the universities under MOE in China could benefit economically from economies of scale and scope. For ray economies of scale, there is no definite evidence to exclude the use of the single product model. The results from both single and multiple output models do not differ significantly. So, if all the data required for the three-output model are not available, either through limitation of the data-set or reliable information on research output, the single-equation model can also give a simple and approximate estimation. This suggests that more new empirical studies of the single product cost function should be undertaken.

\section{References}

Baumol, W. J., Panzar, J. C., \& Willig, R. D. (1982). Contestable markets and the theory of industry structure. New York: Harcourt Brace Jovanovich.

China Education and Research Network. (2004). Universities list for "211 project". Retrieved from http://www.edu.cn/20030911/3090737.shtml

Cohn, E., Rhine, S. L. W., \& Santos, M. C. (1989). Institutions of higher education as multi-product firms: Economies of scale and scope. Review of Economics and Statistics, 71, 284-290.

De Groot, H., McMahon, W. W., \& Volkwein, J. F. (1991). The cost structure of American research universities. Review of Economics and Statistics, 73, 424-431.

Development Department of the Ministry of Education. (2000). China education statistics yearbook. Beijing: China Statistic Press.

Duch, N., Parellada, M., \& Polo, J. (2010). Economies of scale and scope of university research and technology transfer: A flexible multi-product approach (Working paper No. 51 IEB Institut d'Economia de Barcelona, Spain).

Dundar, H., \& Lewis, D. R. (1995). Departmental productivity in American universities: Economies of scale and scope. Economics of Education Review, 14, 199-244.

Glass, J. C., McKillop, D. G., \& Hyndman, N. (1995). Efficiency in the provision of university teaching and research: An empirical analysis of UK universities. Journal of Applied Econometrics, 10(1), 61-72.

Gujarati, N. D. (1995). Basic econometrics (3rd ed.). New York: McGraw-Hill, Inc.

Hashimoto, K., \& Cohn, E. (1997). Economies of scale and scope in Japanese private universities. Education Economics, 5(2), 107-115.

Hou, L. L., Li, F. L., \& Min, W. F. (2009). Multi-product total cost functions for higher education: The case of Chinese research universities. Economics of Education Review, 28, 505-511.

Izadi, H., Johnes, G., Oskrochi, R., \& Crouchley, R. (2002). Stochastic frontier estimation of a CES cost function: The case of higher education in Britain. Economics of Education Review, 21, 63-71.

Johnes, G. (1996). Multiproduct cost functions and the funding of tuition in UK universities. Applied Economics Letters, 3, 557-561.

Johnes, G. (1997a). Costs and industrial structure in contemporary British higher education. Economic Journal, 107, 727-737.

Johnes, G. (1997b). Costs in UK higher education: A system-wide perspective (Unpublished paper in Centre for Economic Reform and Transformation, Heriot-Watt University).

Johnes, G. (1998). The costs of multi-product organizations and the heuristic evaluation of industrial structure. Socio-economic Planning Sciences, 32(3), 199-209.

Khan, M. S. A. (2012). Stochastic estimation of cost frontier: Evidence from Bangladesh. Journal of Education Economics, 20(2), 211-227.

Koshal, R. K., \& Koshal, M. (1995). Quality and economies of scale in higher education. Applied Economics, 22, 3-8.

Koshal, R. K., \& Koshal, M. (1999). Economies of scale and scope in higher education: A case of comprehensive universities. Economics of Education Review, 18, 269-277.

Koshal, R. K., \& Koshal, M. (2000). Do liberal arts colleges exhibit economies of scale and scope. Education Economics, 8(3), 209-220.

Koshal, R. K., \& Koshal, M. (2001). Multi-product total cost function for higher education: A case of bible colleges. Economics of Education Review, 20, 297-303. 
Laband, N., \& Lentz, F. (2003). New estimates of economies of scale and scope in higher education. Southern Economic Journal, 70, 172-183.

Lewis, D. R., \& Dundar, H. (1995). Economies of scale and scope in Turkish universities. Education Economics, 3(2), $133-158$.

Lloyd, P. J., Morgan, M. H., \& Williams, R. A. (1993). Amalgamation of universities: Are there economies of scale or scope. Applied Economics, 25, 1081-1092.

$\begin{array}{llllllll}\text { Ministry of } & \text { Education } & \text { (2004). The }] . \quad \text { Thiversities } & \text { list. Retrieved from }\end{array}$ http://news.xinhuanet.com/school/2004-04/16/content_1423772.htm

Nelson, R., \& Heverth, K. T. (1992). Effect of class size on economies of scale and marginal costs in higher education. Applied Economics, 24, 473-482.

Panzar, J. C., \& Willig, R. D. (1981). Economies of scope. American Economic Review, 71, 268-272.

Worthington, A. C., \& Higgs, H. (2011). Economies of scale and scope in Australian higher education. Higher Education, 61, 387-414.

Wu, S. L., Lu, J., \& Guo, S. L. (2001). Evaluation on China's universities 2001 (2001 zhongguo daxue pingjia). Science of Science and Science Technology Management [kexuexue Yu Kexuejishu Guanli], 6, 38-50. 